\title{
Struktur und Funktion des braunen Fettgewebes der Ratte im Mg-Mangel
}

\author{
Von Th. Günther, J. Schmalbeck, F. Dorn und H. J. Merker ${ }^{1}$ ) \\ Zentralinstitut fiir Biochemie und Biopbysik, Pbjsiologisch-Chemisches Institut und \\ II. Anatomisches Institut der Freien Universität Berlin
}

(Eingegangen am 29. Februar/15. Juli 1972)

Nach einer Abnahme der Serum Mg-Konzentration infolge Mg-armer Ernährung sind in den braunen Fettzellen der Ratte die Zahl und Größe der Fetteinschlüsse stark reduziert sowie die Mitochondrien stark geschwollen. Diese Veränderungen lassen sich mit einer erhöhten Lipolyse, die auch durch die Lipidanalyse bestätigt wurde, und einer Entkopplung der oxidativen Phosphorylierung in vivo erklären. Als Ursache wird eine vermehrte Bildung von 3', 5'-AMP im Mg-Mangel diskutiert.

\section{The structure and function of the brown fat tissue of the rat in Mg-deficiency}

When the serum concentration of magnesium decreases as a result of an $\mathrm{Mg}$-deficient diet, the size and number of the fat inclusions is markedly decreased in the brown fat cells and the mitochondria are markedly swollen. These changes can be explained on the basis of increased lipolysis, which was confirmed by lipid analysis, and an uncoupling of oxidative phosphorylation in vivo. This is thought to be caused by the increased synthesis of $3^{\prime}, 5^{\prime}$-AMP in Mg-deficiency.

Das braune Fettgewebe spielt eine Rolle bei der Wärmeproduktion des Organismus. Kälte-adaptierte oder neugeborene Tiere haben einen höheren Gehalt an braunem Fettgewebe. Bei diesen Tieren wird ein größerer Teil der Körperwärme unter Beteiligung des braunen Fettgewebes (direkt oder vielleicht auch indirekt durch Einwirkung auf andere Organe (1)) ohne Kältezittern erzeugt. Besonders aktiv ist das braune Fettgewebe beim Erwachen aus dem Winterschlaf:

Der Stoffwechsel und die Wärmebildung des braunen Fettgewebes stehen unter der Kontrolle des sympathischen Nervensystems bzw. unter dem Einfluß von Noradrenalin. Noradrenalin erhöht infolge einer Stimulierung der Adenylcyclase die Bildung von 3', 5'-AMP, welches selbst und über eine Erhöhung der Fructosediphosphat-Konzentration die Triglyceridlipase aktiviert. Die aus Triglyceriden in größerer Menge freigesetzten Fettsäuren sollen durch Aufheben der Phosphat-Acceptor-Kontrolle oder durch Entkopplung der oxidativen Phosphorylierung in den wahrscheinlich besonders empfindlichen Mitochondrien des braunen Fettgewebes eine vermehrte Oxidation der freien Fettsäuren und eine vermehrte Wärmebildung im braunen Fettgewebe selbst bewirken $(1,2,3,4)$. Hierfür werden verschiedene biochemische Mechanismen angenommen, u. a. sollen dabei die freien Fettsäuren die Permeabilität der Mitochondrien-Membran erhöhen und zu einem vermehrten Efflux von $\mathrm{K}$ führen. Als Folge könnte unter ATP-Verbrauch ein verstärkter $\mathrm{K}$-Transport zurück in die Mitochondrien erfolgen $(5,6,7)$. Das anfallende ADP entspräche einer Entkopplung. Alle bisherigen Hypothesen zur Erklärung der Thermogenese werden jedoch angezweifelt (7).

Zwischen dem Wärmehaushalt und $\mathrm{Mg}$ bestehen bisher nicht näher erklärbare Beziehungen. $\mathrm{Zu}$ Beginn des
Winterschlafes ist die $\mathrm{Mg}$-Konzentration im Serum erhöht (8). Winterschlaf und somit Senkung der Körpertemperatur kann experimentell durch $\mathrm{Mg}$-Injektion eingeleitet werden (9). Bei Nicht-Winterschläfern senkt Injektion von $\mathrm{Mg}$ ebenfalls die Körpertemperatur (10), was u. a. durch verminderte Atmung (Wärmebildung) erklärt wurde (10).

Kälteexposition führt zu einem Ansteigen der Mg-Konzentration im Serum $(11,12)$. Wird bei kälteexponierten Tieren die Serum-Mg-Konzentration zusätzlich erhöht, nimmt ihre Kältetoleranz ab (13). Die Kältetoleranz wird aber auch durch Entfernen des braunen Fettgewebes herabgesetzt (14). Um die Wirkung des $\mathrm{Mg}$ auf das braune Fettgewebe in vivo besser kennenzulernen, untersuchten wir dieses Gewebe bei Ratten, deren $\mathrm{Mg}$ Konzentration im Serum durch $\mathrm{Mg}$-arme Ernährung stark herabgesetzt war. Um die untersuchten Eigenschaften des braunen Fettgewebes im $\mathrm{Mg}$-Mangel mit den besser bekannten Wirkungen einer vermehrten Wärmebildung vergleichen zu können, wurden normal ernährte Tiere außerdem einer akuten Kältebelastung unterworfen.

Das braune Fettgewebe hat einen hohen Gehalt an weißen Fettzellen. Zur Spezifizierung zwischen beiden Zellarten, zum Vergleich mit den Lipidanalysen und um Hinweise auf funktionelle Änderungen im intakten Tier zu erhalten, haben wir das braune Fettgewebe histochemisch mittels Lipidfärbung und elektronenmikroskopisch untersucht.

Als zusätzlichen Hinweis auf eine in vivo abgelaufene Lipolyse wählten wir den Gehalt an Neutralfett, das 90\% der Gesamtlipide im braunen Fettgewebe darstellt, sowie die Konzentration an freien Fettsäuren im Serum.

1) Mit Unterstützung durch die DFG im Rahmen des Sonderforschungsberciches 29 . 
Im Mg-Mangel tritt in einigen Organen (15), nicht in allen (16), eine Änderung des $\mathrm{Na}$-, $\mathrm{K}$ - und $\mathrm{Mg}$-Gehaltes ein. Da Noradrenalin z. B. in der Leber den K-Efflux erhöht (17) und somit die intrazelluläre K-Konzentration herabsetzen könnte und die Wirkung des Noradrenalin in vitro $u$. a. von $\mathrm{K}$ und $\mathrm{Mg}$ abhängt (5), bestimmten wir auch diese Größen.

\section{Methodik}

Dic Versuche wurden an $150-200 \mathrm{~g}$ schweren männlichen Wistar-Ratten durchgeführt. Die Versuchstiere wurden vier Wochen bei Raumtemperatur (etwa $23^{\circ} \mathrm{C}$ ) mit einer $\mathrm{Mg}$-reichen bzw. Mg-armen Versuchsdiät ad libitum gefüttert. Alle Versuchstiere crhielten destilliertes Wasser. Die Zusammensetzung der Versuchsnahrung wurde an anderer Stelle beschrieben (15). Der $\mathrm{Mg}$-Gehalt der Mg-armen Nahrung betrug $1,5 \mathrm{mmol} / \mathrm{kg}$.

Eine Kontrollgruppe erhielt bei Raumtemperatur die Mg-reiche Diät in reduzierter Menge, so daß sie die gleiche Gewichtszunahme wie die $\mathrm{Mg}$-arm bei Raumtemperatur gehaltenen Tiere aufwies. Bei der akuten Kälteexposition wurden normal ernährte Ratten $3 \mathrm{~h}$ mit nassem Fell bei $0^{\circ} \mathrm{C}$ gehalten.

Das braune Fettgewebe wurde den Ratten aus der Interscapularregion (für die morphologischen Untersuchungen auch aus der Nachbarschaft der thorakalen Aorta) entnommen und für die Analysen sofort in flüssigem $\mathrm{N}_{2}$ eingefroren bzw. für die Morphologie sofort fixiert.

Die Fixierungslösung bestand aus 3proz. Glutaraldehyd plus 3\% Paraformaldehyd in Cacodylatpuffer, $0,1 \mathrm{~mol} / 1, \mathrm{pH} \mathrm{7,4}$. Nach erneuter Fixierung in 1proz. $\mathrm{OsO}_{4}$-Lösung und Entwässerung in der Acetonreihe erfolgte die Einbettung in Micropal (Fa. Ferak-Berlin). Die Schnitte wurden mit LKB- und ReichertMikrotomen, die Aufnahmen mit Siemens-Elmiskopen I und Ia hergestellt. Kontrastierung: Uranylacetat-Bleicitrat.' Zur lichtmikroskopischen Kontrolle benutzten wir etwa 0,5 bis $1 \mu \mathrm{m}$ dicke Schnitte, die mit Giemsa-Lösung bei $60^{\circ} \mathrm{C}$ für eine Minute gefärbt wurden.

Der Wassergehalt wurde aus der Gewichtsdifferenz vor und nach Gefriertrockung ermittelt. Der Na- und K-Gehalt wurde mittels Flammenphotometrie, det $\mathrm{Mg}$-Gehalt mit Hilfe der Atomabsorptionsspektrometrie jeweils nach Standard-Methoden bestimmt. Die Lipide wurden nach Folch et al. (18) extrahiert. Der Gehalt an neutralen Glyceriden wurde nach Verseifung durch enzymatische Bestimmung des freigesetzten Glycetins bestimmt (19). Das mittlere Molekulargewicht der neutralen Glyceride wurde nach den Angaben von Chalvardjian (20) errechnet. Die Korzentration von freien Fettsäuren im Serum wurde nach Dole et al. (21) bestimmt.

\section{Ergebnisse}

Morphologie

Die Zellen des normalen braunen Fettgewebes sind im lichtmikroskopischen Bild durch zahlreiche, bis zu $10 \mu \mathrm{m}$ große Fetteinschlüsse und den meist zentralliegenden großen Kern charakterisiert. Eine reichliche Kapillarversorgung ist vorhanden (Abb. 1a). Im elektronenmikroskopischen Bild fällt die Fülle großer ovaler Mitochondrien auf,' die zahlreiche und dicht gepackte, vorwiegend senkrecht zur Längsachse angeordnete Cristae enthalten (Abb. 2). In der Matrix zwischen den Cristae kommen einzelne Granula von $8-12 \mathrm{~nm}$ Größe vor. Der Inhalt der Fetteinschlüsse ist überwiegend homogen und von mittlerer Elektronendichte. Eine begrenzende Membran ist nicht mit Sicherheit nachzuweisen. Häufig liegen Mitochondrien den Fetteinschlüssen ohne deutliche Grenze dicht an. Im übrigen

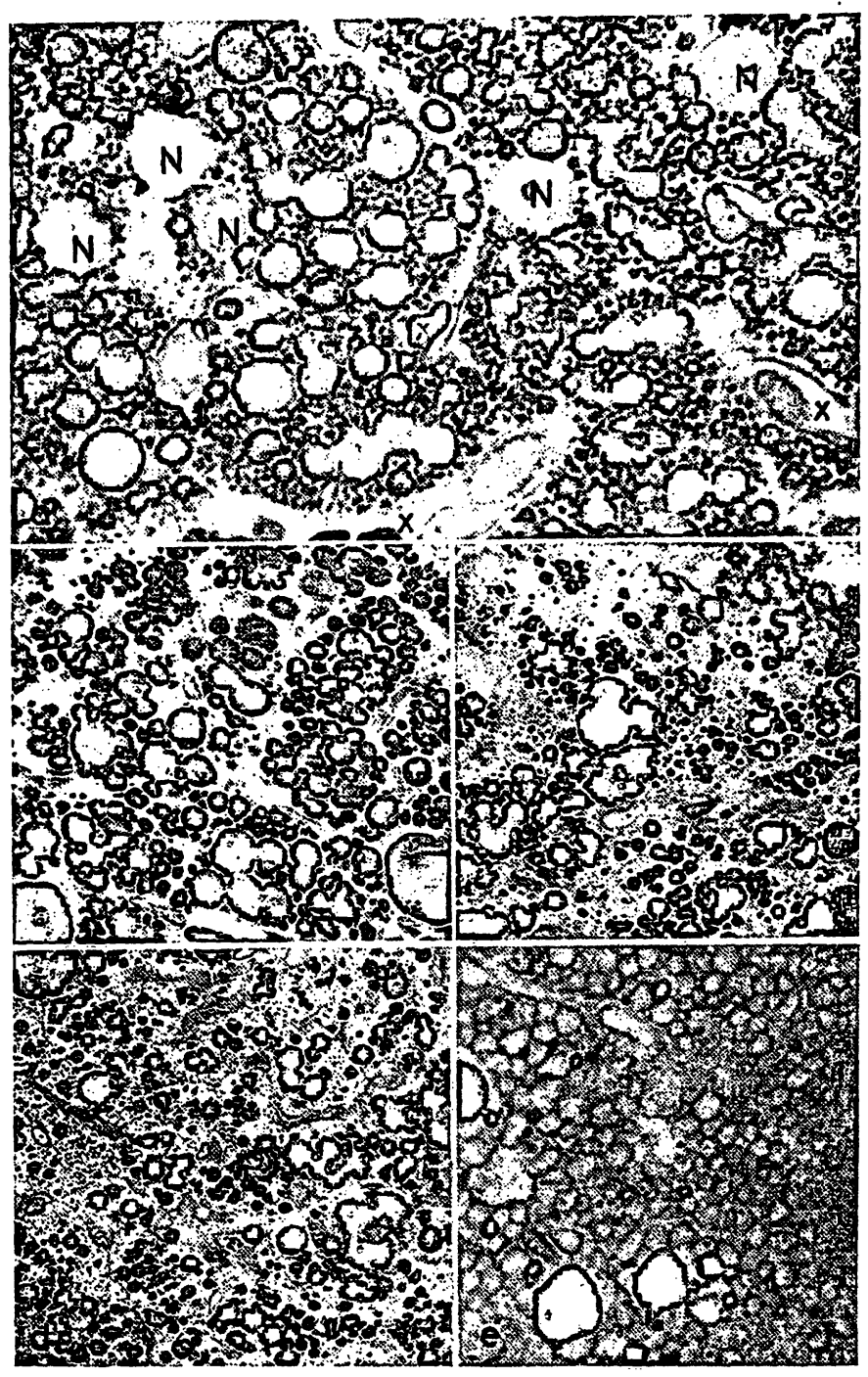

Abb. 1

Lichtmikroskopische Aufnahmen von braunem Fettgewebe der Ratte nach Micropal-Einbettung und Giemsa-Färbung, Schnittdicke etwa $1 \mu \mathrm{m}$

a) (oben) Normales interscapulares braunas Fettgewebe. Große Kerne $(N)$, reichlich Kapillaren (x), Fetteinschlüsse bis zu einer Größe von b) (Mitte, links) $10 \mu \mathrm{m}$ Vergrößerung $1: 700$

b) (Mitte, links) Normales para-aortales braunes Fettgewebe Vergrößerung 1:400

c) (Mitte, rechts) Para-aortales braunes Fettgewebe nach akuter Kältebelastung $\left(3 \mathrm{~h}\right.$ bei $0^{\circ} \mathrm{C}$ mit nassem Fell). Verringerung und Verkleined) (unten, links) Para-aortales braunes Fettüse

deutlicher Verringra-aortales braunes Fettgewebe im $\mathrm{Mg}$-Mangel mit deutlicher Verringerung und Verkleinerung der Fetteinschlüsse. Vakuo-
lige Veränderung des Cytoplasma durch Schwellung der Mitochondrien Vergrößerung $1: 400$

e) (unten, rechts) Wie d). Vergrößerung 1:700

Cytoplasma finden sich die anderen typischen Zellorganellen nur in geringer Zahl. Darüberhinaus sind die Plasmamembranen der braunen Fettzellen, besonders die der Kapillar-Endothelzellen durch ausgeprägte Vesikulationsvorgänge (Pinocytose) charakterisiert. Marklose Nervenfasern mit engem räumlichen. Kontakt zu den braunen Fettzellen und Anhäufungen von „,densecore"-Granula in den Endabschnitten der Nervenfasern kommen reichlich vor $(4,22,23,24)$.

Unter den Bedingungen des $\mathrm{Mg}$-Mangels kommt es $\mathrm{zu}$ einer sehr starken Verringerung der Fetttropfen (Abb. 3). Während in den $1 \mu \mathrm{m}$ dicken Schnitten jede normale Zelle pro Schnittebene 15 bis 30 Fetteinschlüsse enthält, deren Durchmesser zwischen 5 ụnd $10 \mu \mathrm{m}$ variiert, lassen sich im Mg-Mangel höchstens 


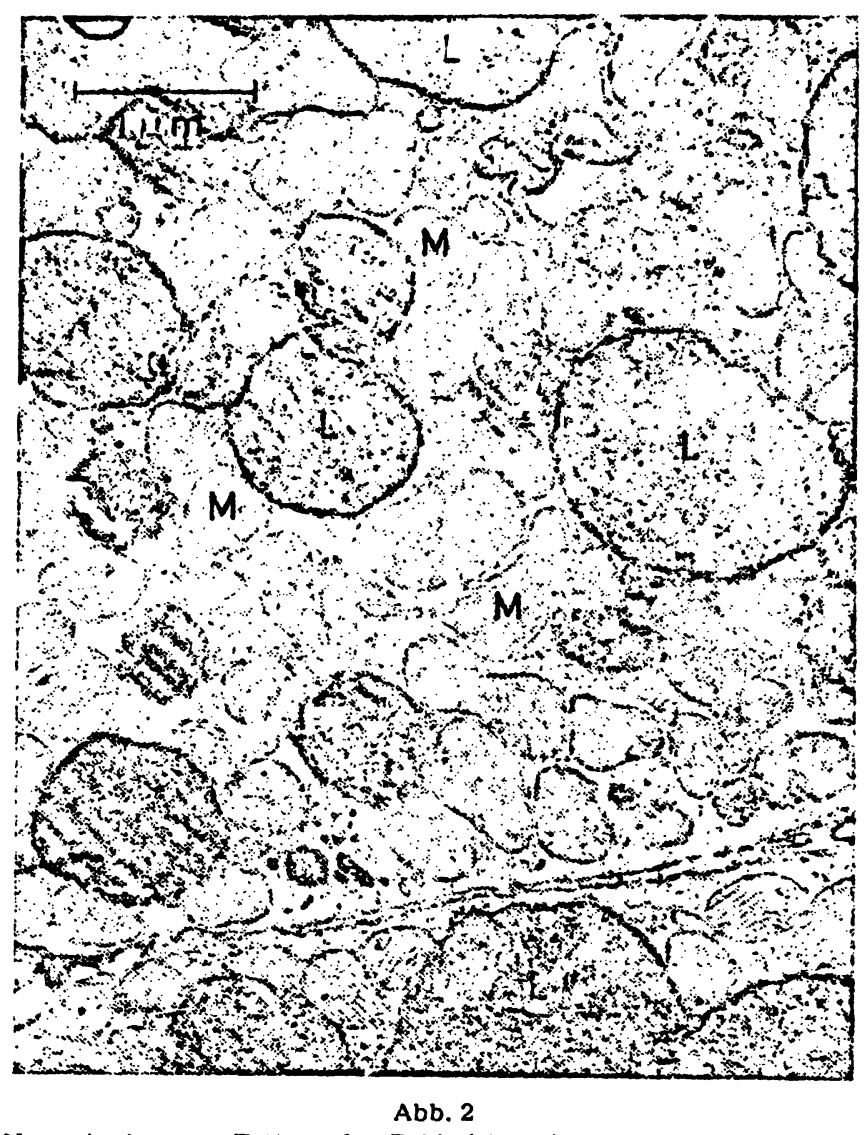

Normales braunes Fettgewebe. Zahlreiche cristaereiche Mitochondrien (M) und unterschiedlich große Fetteinschlüsse (L)
Vergrößerung 1:17000

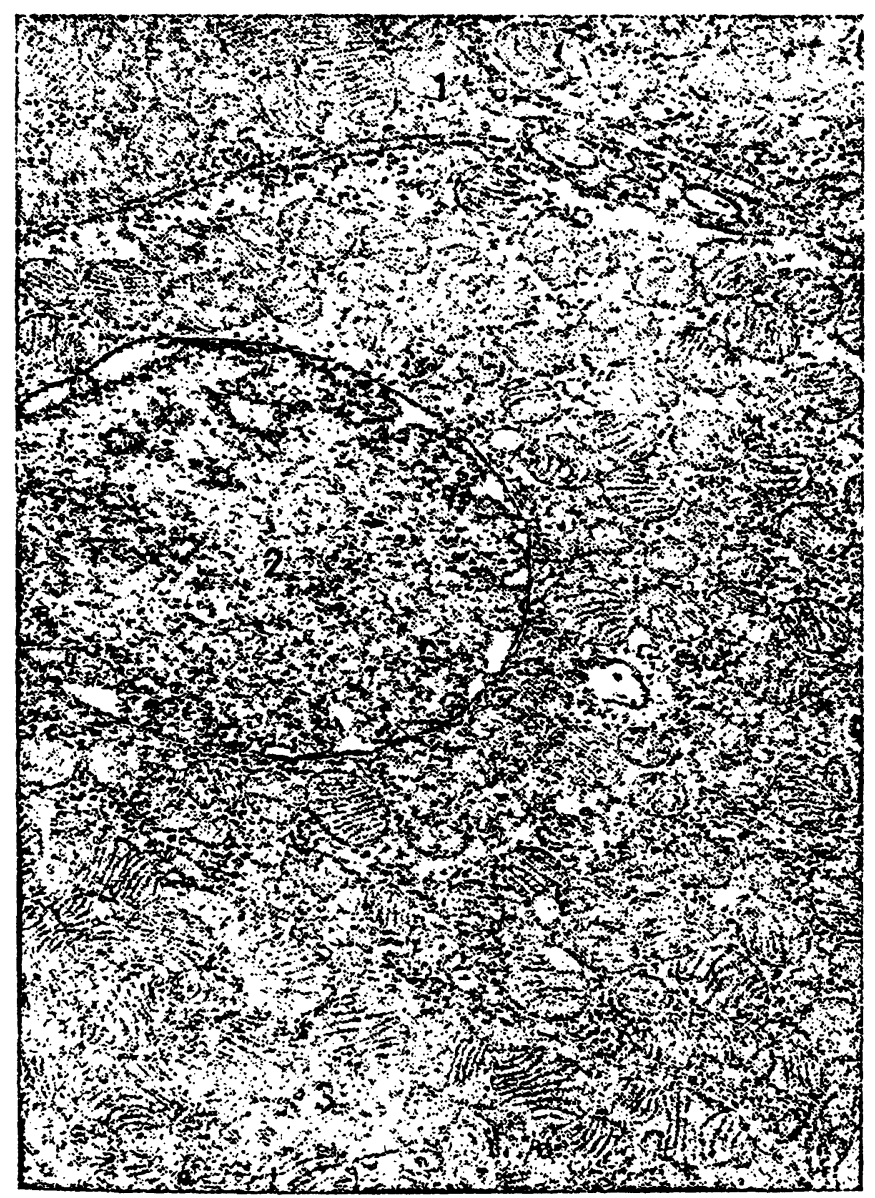

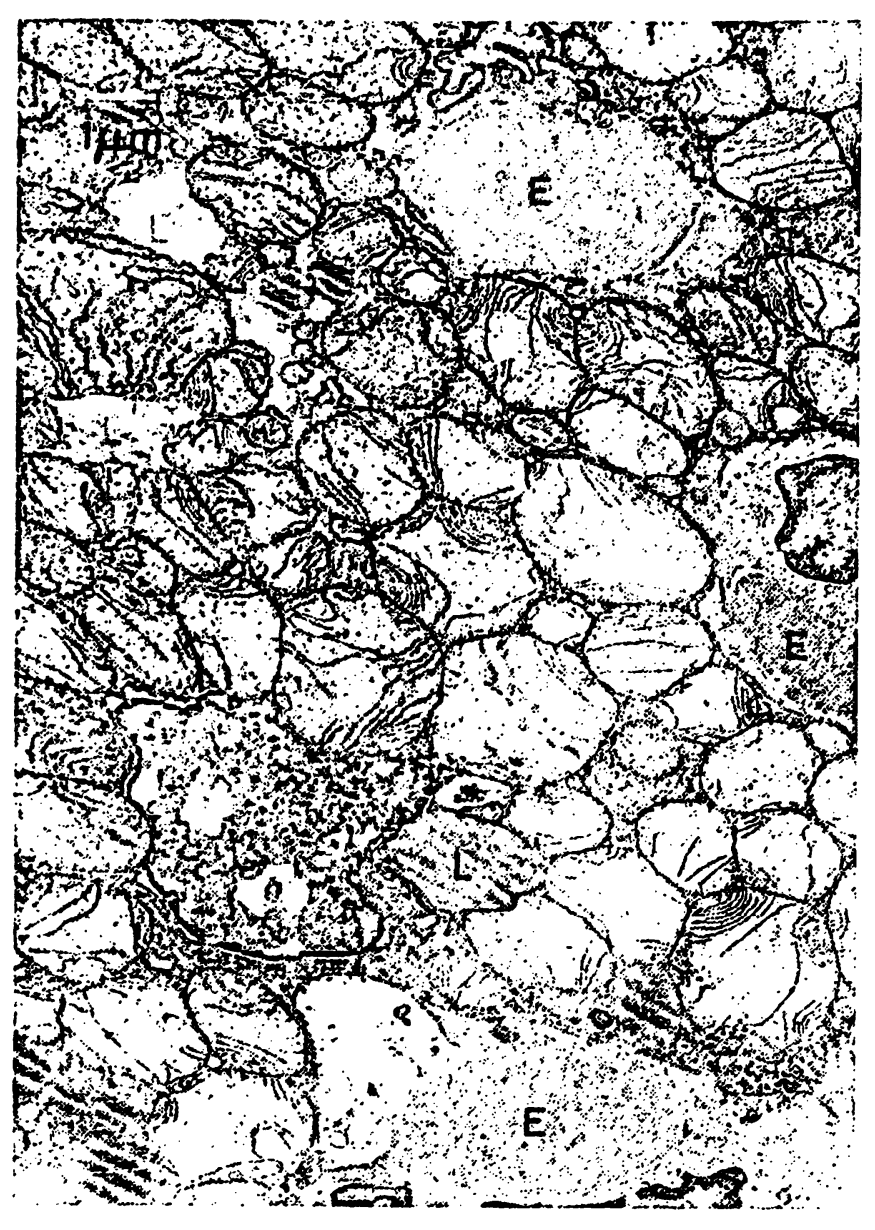

Abb. 4

Wie Abb. 3. Extreme Schwellung der Mitochondrien. Wenige kleine Fetteinschlüsse (L). E $=$ Erythrocyten in Kapillaren

6 Einschlüsse nachweisen, die nur bis zu $5 \mu \mathrm{m}$ groß sind. Bereits im lichtmikroskopischen Bild fallen in einem Teil der Zellen zahlreiche kleinere Vakuolen auf, die im Elektronenmikroskop als geschwollene Mitochondrien identifiziert werden können (Abb. 1d, 1e, 3). Die Mitochondrien jeder Zelle verhalten sich einheitlich. Sie sind entweder alle wenig oder durchweg stark geschwollen. Dabei sind die Mitochondrien aus etwa $40 \%$ der braunen Fettzellen mit keinen oder nur noch 1-2 Fetteinschlüssen pro Zelle besonders stark verändert. Der Durchmesser der geschwollenen Mitochondrien ist oft extrem vergrößert (Abb. 4). Dadurch wird das Cytoplasma zwischen ihnen auf sehr enge Räume zusammengepreßt oder die Membranen benachbarter Mitochondrien berühren sich sogar. Die Matrix in diesen geblähten Partikeln ist verschwunden. Durch die Schwellung, die die innere Mitochondrienkammer betrifft, sind die Cristae in der Peripherie oder nur in umschriebenen Arealen der Mitochondrien lokalisiert. Weite Gebiete der Mitochondrien sind deshalb optisch leer oder nur mit locker verteiltem, fein granulärem Material gefüllt. Häufig finden sich Membranstrukturen

Abb. 3

Zellen des braunen Fettgewebes im Mg-Mangel (aus der para-aortalen Region). Völliges Fehlen der Fetteinschlüsse (Entspeicherung). Im Anschnitt der Zellen 1 und 2 annăhernd normale Mitochondrienstruktur. Im Anschnitt 3 Scliwellung der Mitochondrien
Vergrößerung 1:7000 
oder Filamente, die geschichtet oder in paralleler Packung angeordnet parakristallinen Einschlüssen ähnlich sind. Derartige Veränderungen sind auch bei akuter Kältebelastung zu sehen (25). Die Morpḥologie des Kernes hat sich gegenüber den Kontrollen nicht sichtbar verändert. Auffällig ist eine Zunahme der Vesikulationsprozesse und eine Verdichtung des Inhaltes der entstehenden Vesikel unter den Bedingungen des $\mathrm{Mg}$ Mangels in den Endothelzellen der Kapillaren, was auf vermehrte Transportprozesse durch die Membranen schließen läßt.

Nach akuter Kältebelastung (3 h mit nassem Fell bei $0^{\circ} \mathrm{C}$ ) fanden wir qualitativ gleiche Veränderungen. Die Zahl und Größe der Fetteinschlüsse war im gleichen Maße wie beim Mg-Mangel reduziert. Die Mitochondrien der braunen Fettzellen waren im Kältestreß ebenfalls geschwollen, dabei hatten aber nur etwa $20 \%$ der Fettzellen stark geschwollene Mitochondrien. Es waren dies wieder die Zellen mit der stärksten Entspeicherung. Die Mitochondrien-Schwellung erreichte nicht das Aus$\mathrm{maß}$ wie beim Mg-Mangel.

Spezifität der morphologischen Veränderungen im Mg-Mangel

Um zu prüfen, ob die Veränderungen des braunen Fettgewebes im Mg-Mangel nicht durch eine geringere Nahrungsaufnahme der Mg-Mangeltiere bedingt sind, haben wir in Parallelversuchen Ratten mit der gleichen, aber $\mathrm{Mg}$-reichen Diät so gefüttert, daß sie den gleichen Gewichtszuwachs wie die Mg-arm ernährten Ratten aufwiesen. Dabei zeigte sich, daß bei verminderter Nahrungsaufnahme die Zahl und Größe der Fetteinschlüsse in den braunen Fettzellen nur geringfügig abnahm. Die Feinstruktur ließ keine Abweichungen erkennen, nur die Zahl der Mitochondrien, die einen engen täumlichen Kontakt zu den Fetteinschlüssen aufwiesen, schien zugenommen zu haben. Eine verminderte Nahrungsaufnahme als Ursache für die morphologischen Änderungen des braunen Fettgewebes im Mg-Mangel läßt sich deshalb ausschließen.

Die beschriebenen morphologischen Veränderungen der braunen Fettzellen im chronischen Mg-Mangel scheinen charakteristisch für diese Zellen zu sein, denn an anderen Organen und speziell an den weißen Fettzellen waren sie nicht zu sehen. Man muß jedoch be- denken, daß eine Verkleinerung des einen großen Fetttropfens in den weißen Fettzellen im histologischen bzw. elektronenmikroskopischen Bild schwer zu beurteilen ist. Artefakte durch die Fixation als Ursache der Schwellung sind auszuschließen, da die Schwellung bei den identisch behandelten Kontrolltieren nicht auftrat und in denselben Schnitten, in denen noch andere Zellarten (weiße Fettzellen, Bindègewebszellen) vorliegen, nur die Mitochondrien der braunen Fettzellen betroffen waren.

\section{Lipidgehalt}

Die Morphologie des braunen Fettgewebes im MgMangel weist auf eine vermehrte Lipolyse hin. Damit würde übereinstimmen, daß bei den $\mathrm{Mg}$-Mangeltieren die Konzentration an freien Fettsäuren im Serum mit $0,43 \pm 0,02 \mathrm{mmol} / 1$ signifikant höher als in der Kontrollgruppe mit $0,32 \pm 0,02 \mathrm{mmol} / \mathrm{l}$ war. Unklar ist in diesem Zusammenhang, ob die freien Fettsäuren der braunen Fettzellen z. T. nach außen gelangen. Dies wurde von einigen Untersuchern $(6,26)$ gefunden, aber von WirLIAMson angezweifelt (27).

Der Lipid- und Wassergehalt im braunen Fettgewebe der Normaltiere entspricht den Werten der Literatur (21). Bei den Mg-Mangelratten und den kälteexponierten Ratten ist der Gehalt an Neutralfetten niedriger als bei den Kontrolltieren (Tab. 1).

\section{Elektrolytgehalt}

Nach Mg-armer Ernährung sank die Serum-Mg-Konzentration von $0,95 \pm 0,04 \mathrm{mmol} / \mathrm{l}$ auf 0,35 上 0,03 $\mathrm{mmol} / \mathrm{l} \mathrm{ab}$. Im braunen Fettgewebe traten dabei keine signifikanten Änderungen im Wasser- und Elektrolytgehalt auf. Nach akuter Kältebelastung war der $\mathrm{Na}$ Gehalt erhöht und der $\mathrm{K}$ - und $\mathrm{Mg}$-Gehalt abgesunken. $\mathrm{Da}$ bei diesen Tieren gleichzeitig der $\mathrm{H}_{2} \mathrm{O}-$ Gehalt im braunen Fettgewebe stark zugenommen hatte, sind diese Veränderungen mit einer vermehrten Durchblutung und Zunahme an extrazellulärer Flüssigkeit zu erklären, wie sie von SELYE (28) und SUTER (29) bei Kältebelastung gefunden wurde. $\mathrm{Da}$ die Größe der extrazellulären Flüssigkeit nicht direkt bestimmt wurde, wird auf eine Differenzierung $z$ wischen extra- und intrazellulärem Elektrolytanteil und auf eine Diskussion der möglichen Funktion der intrazellulären Elektrolyte im Stoffwechsel der braunen Fettzellen beim $\mathrm{Mg}$-Mangel verzichtet.

Tab. 1

Wasser-, Neutralfett-, Na-, K- und Mg-Gehalt des interscapulären braunen Fettgewebes von Mg-reich, Mg-arm ernährten Ratten und von kältegestreßten Ratten. Angegeben sind der Mittelwert \pm mittlerer Fehler des Mittelwertes $\left( \pm \sqrt{\frac{\sum(\bar{x}-x i)^{2}}{n(n-1)}}\right)$, bezogen auf Feuchtgewicht (FG). Die Werte für Neutralfett wurden außerdem auf Trockengewicht (TG) umgerechnet.

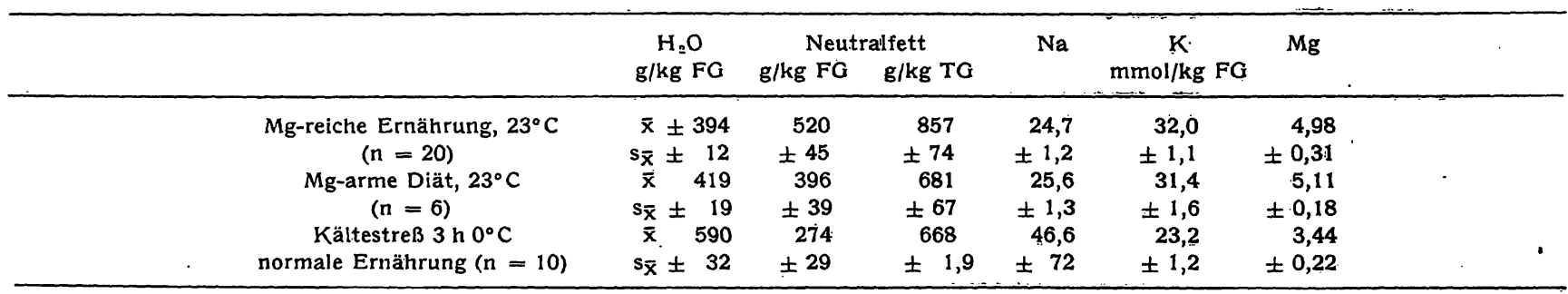




\section{Laborautomatisation - konsequent und zukunftssicher}

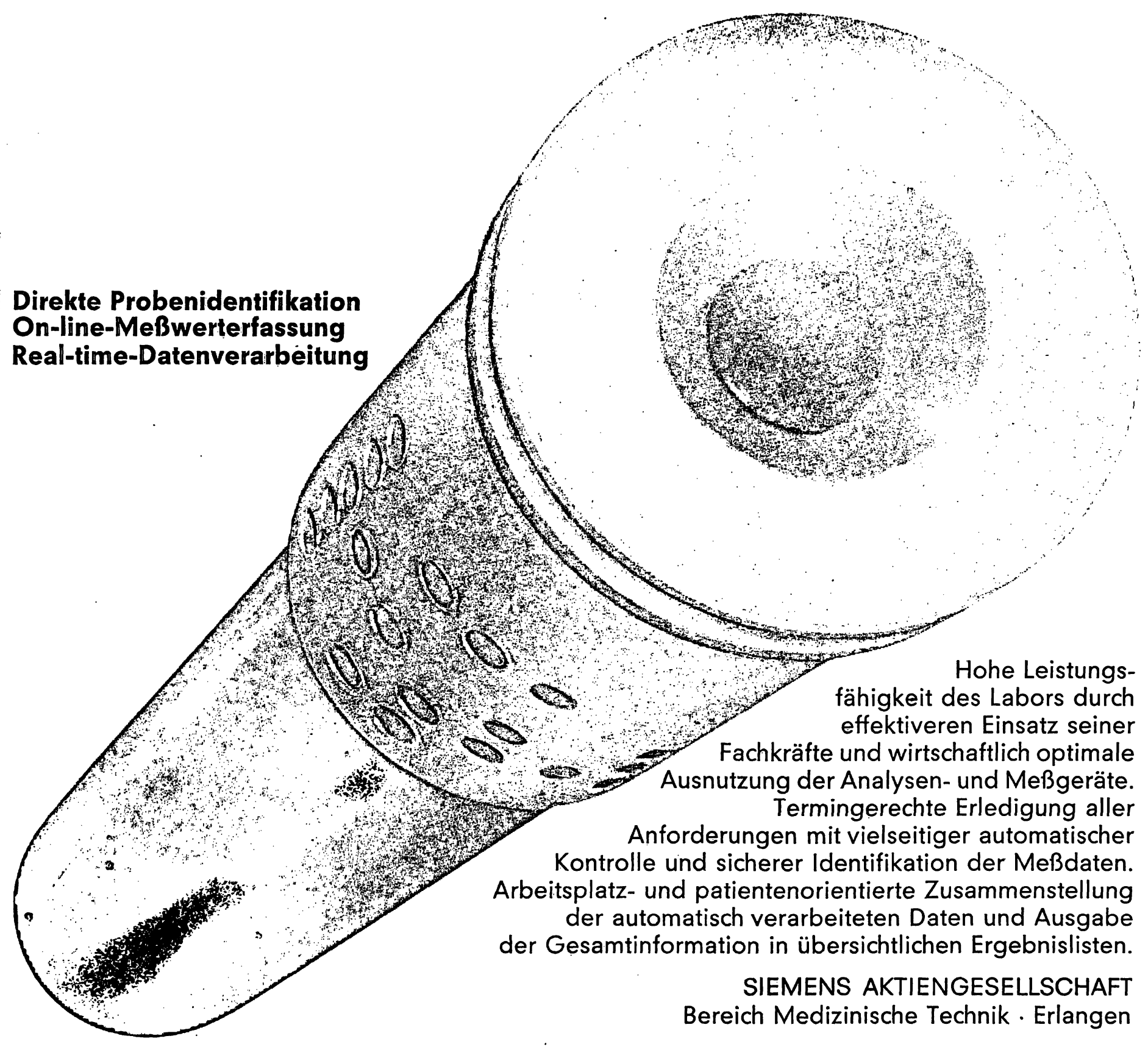

mint dem SILAB-Systern Von Siemens 


\section{Präzisionskontrollen.}

Humanseren, Normal - Pathologisch.

Humanserum " $\mathrm{Q} P a k$ " für Analyșeautomaten.

\section{Richtigkeitskontrollen.}

Humanseren, Normal ${ }^{\star}$ - Pathologisch* Spezial.

Humanserum "QPak" für Analyseautomaten. Multi-Enzym-Referenzserum.

Bilirubinkontrolle mit erhöhten Werten.

Cholesterinkontrolle mit erhöhten Werten.

Kontrollurine. Kontroll-Liqor.

HB-Referenzstandard und -Kontrolle.
Mit HYLAND-Kontrollreagenzien können Sie mehr als 70 verschiedene Bestimmungen überprüfen.

Verlangen Siè bitte unsere Informationsunterlagen.

\section{$\boldsymbol{P}$}

HYLAND

TRAVENOL INTERNATIIONAL GMBH 8 München 2, Postfach 202429

Telefon (0811) 539376

\section{* Mit Europawerten}

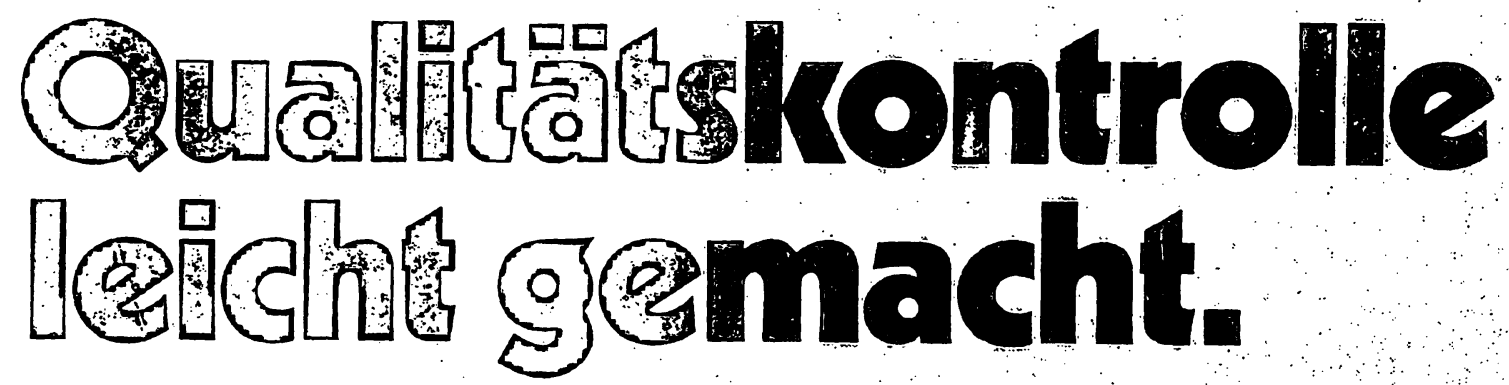

\section{HYLAND Richtigkeits- und Präzisionskontrollen.}

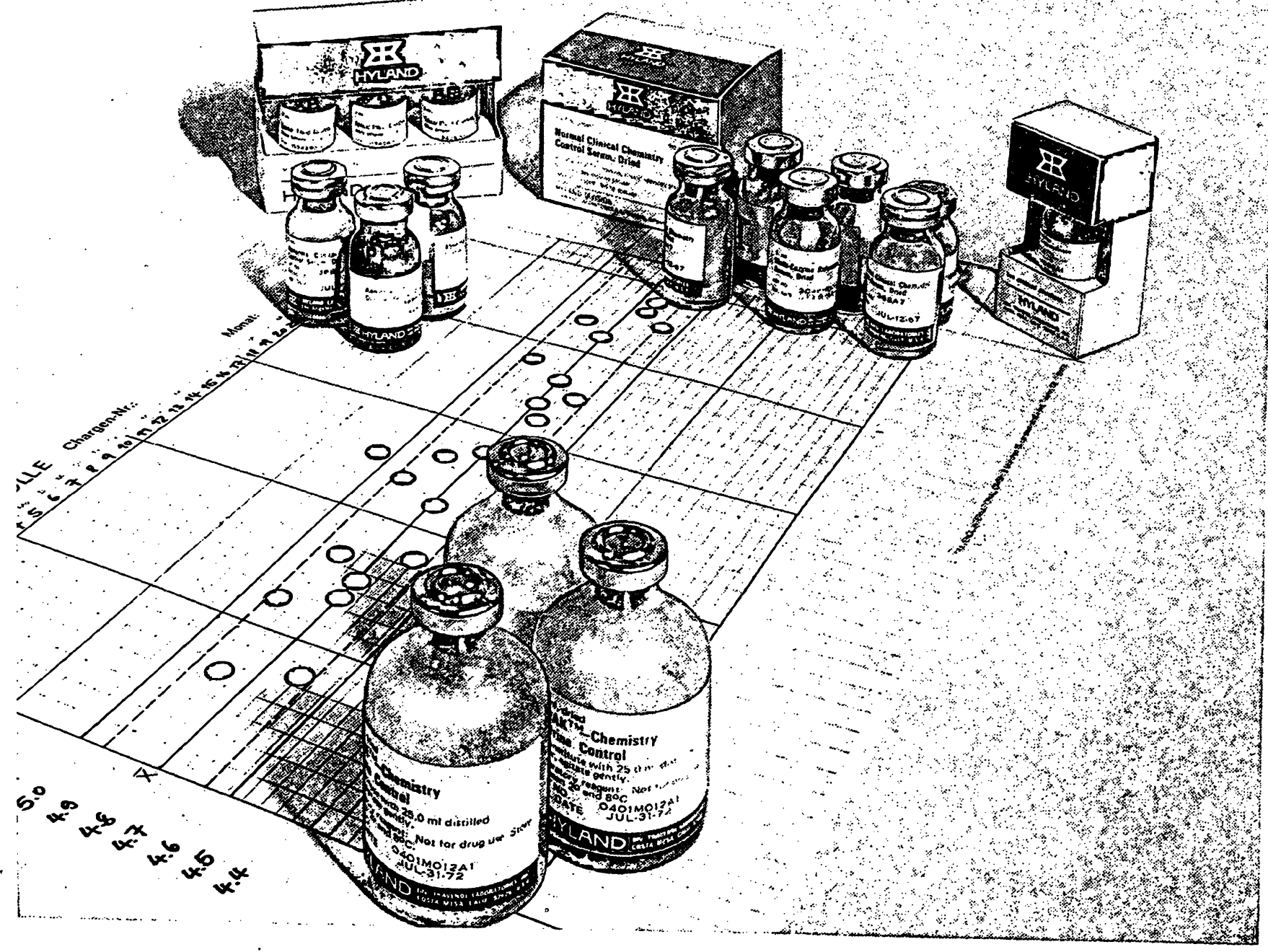




\section{Diskussion}

Zwischen den morphologischen und chemischen Befunden bei den verschiedenen Tiergruppen ist nur eine qualitative Beziehung herzustellen. Der geringe quantitative Unterschied in der Mitochondrienschwellung zwischen chronischem Mg-Mangel und akutem Kältestreß erscheint verständlich, da es sich um völlig verschiedene Bedingungen und Belastungen handelt. Das braune Fettgewebe der normalen Ratten enthielt nach mikroskopischer Abschätzung ein Drittel weiße Fettzellen, nach FArN et al. sogar bis zu 75\% (30). Bei der Morphologie werden nur braune Fettzellen allein betrachtet, die Analysen erfassen jedoch sämtliche Zellarten im Gewebe. Da nach den morphologischen Bildern die weißen Fettzellen kaum verändert sind, ist z. B. die Lipidabnahme an Hand der Lipidfärbung in den braunen Fettzellen sicher stärker, als sie sich in den Analysenwerten für den Neutralfettgehalt des braunen Fettgewebes ausdrückt. Ein unterschiedlicher Gehalt an weißen Fettzellen in den Tiergruppen würde die Korrelation zwischen Morphologie und Analysenwerten zusätzlich beeinträchtigen.

Die morphologischen Ergebnisse und die Lipidanalysen zeigen, daß nach einem Absinken der Serum Mg-Konzentration in den braunen Fettzellen eine vermehrte Lipolyse abläuft. Die starke Schwellung der Mitochondrien im Mg-Mangel macht eine Entkoppelung der oxidativen Phosphorylierung in vivo wahrscheinlich. Damit übereinstimmend wurde an Herzmuskelsarcosomen von $\mathrm{Mg}$-Mangeltieren ein vertingerter $\mathrm{P} / \mathrm{O}-\mathrm{Quo}$ tient gefunden $(31,32)$. Akute Kältebelastung und MgMangel führen also zu gleichartigen Veränderungen der Morphologie und des Lipidgehaltes. Akute Kälteexposition bewirkt eine vermehrte Ausschüttung von Noradrenalin aus den reichlich vorhandenen sympathischen Nervenendigungen und vermehrte Bildung von 3', 5'-AMP im braunen Fettgewebe. Im Mg-Mangel kann, wie von einigen Untersuchern vermutet $(33,34)$, ebenfalls vermehrt Noradrenalin freigesetzt werden. Es besteht auch die Möglichkeit, daß durch die Abnahme der Serum-Mg-Konzentration, die die charakteristische Elektrolyt-Veränderung im Mg-Mangel ist (16), $\mathrm{Mg}$ aus Mg-Komplexen der Zellmembran dissoziiert. Dadurch könnte sich die Konformation membrangebundener Proteine ändern und die Aktivität der membrangebundenen Adenylcyclase erhöhen. Eine entsprechende indirekte Beeinflussung der Adenylcyclase von Fettzellen z. B. durch hypotone Schwellung, Phospholipase C, Proteasen oder durch spezifische Hemmung der ebenfalls membrangebundenen $\mathrm{Na}, \mathrm{K}$-ATPase ist bekannt (35). Die vermehrte Lipolyse im braunen Fettgewebe bei $\mathrm{Mg}$-Mangel könnte also analog durch eine erhöhte Konzentration von 3', 5'-AMP hervorgerufen werden.

\section{Literatur}

1. Hinars-Hagen, J. (1970), Adv. Enzyme Regulation 8, 131-151. 2. SMIth, R. E. \& Horwitz, B. A. (1969), Physiol. Rev. 49, 330 bis 425. - 3. Williamson, J. R., Prusiner, S., Olson, M. S. \& FukAMI, M. (1970), Lipids 5, 1-14. - 4. LindBerg, O. (1970), Brown Adipose Tissue, American Elsevier Publishing Company, Inc., New York. - 5. ReED, N. \& FAIN, J. N., (1968) J. Biol. Chem. 243, 6077-6083. - 6. REED, N. \& Fain, J. N. (1970), in: 1 c. (5) p. 207. - 7. Prusiner, S. \& Poe, M. (1970), in: 1. c. (4) p. 263. - 8. Riedesel, M. L. \& Folk, G. E. (1956), Fed. Proc. Fcd. Amer. Soc. Exp. Biol. 15, 151. - 9. Suomalainen, P., Ann. Acad. Sci. Fenn. V. Med.-Anthrop. 153, 7 (1939), zit. nach Walser, A. Erg. Physiol. 59, 185 (1967). - 10. HeaGr, F. W. \& Burton, A. C. (1948), Amer. J. Physiol. 152, 407-416. - 11. Hannon, J. P., Larson, A. M. \& Young, D. W. (1958), J. Appl. Physiol. 13, 239-240. - 12. Neubeiser, R. E., Platner, W. S. \& Shields, J. L. (1961), J. Appl. Physiol. 16, 247-249. - 13. Moussa, S. L. \& BobA, A. (1960), Amer. J. Physiol. 199, 1090 bis 1092. - 14. Leduc, J. \& Rrvert, P. (1969), Review Canad. Biol. 28, 49-73. - 15. GüNther, Th (1970), diese Z. 8, 65-68. 16. Martindale, L. \& Heaton, F. W. (1964), Biochem. J. 92, 119-126. - 17. FrIEdMan, N. \& PARK, C. R. (1968), Proc. Nat. Acad. Sci. 61, 504-508. - 18. FolCh, J., LEEs, M. \& Stonne-Stanley, G. H. (1957), J. Biol. Chem. 226, 497-509.
19. Schmidt, F. H. \& v. DahL, K. (1968), diese Z. 6, 156-159. 20. Chalvardjian, A. M. (1964), Biochem. J. 90, 518-521. 21. Dole, V. P. \& Meinertz, H. (1965), J. Biol. Chem. 235, 2595-2599. - 22. BARgMANN, W., v. HeHN, G. \& LiNDNER, E. (1968), Z. Zellforsch. Mikrosk. Anat. 85, 601-613. - 23. BARNAD, T. (1969), J. Ultrastruct. Res. 29, 311-323. - 24. SutER, E. R. \& StÄUBLI, W. J. (1970), J. Histochem. Cytochem. 18, 100-106. 25. Afzelius, B. A. (1970), in: 1. c. (4) p. 1. - 26. Himms-HAGEN, J. (1969), Pharmacol. Rev. 19, 367-461. - 27. Williamson, J. R. (1970), J. Biol. Chem. 245, 2043-2050. - 28. SeLYE, H. \& Timiras, P. (1949), Nature (London) 164, 745-746. - 29. Suter, E. R. (1969), J. Ultrastruct. Res. 26, 216-221. 30. Fain, J. N., Reed, N. \& Saperstein, R. (1967), J. Biol. Chem. 242, 1887-1894. - 31. Vitale, J. J., Nakamura, M. \& Hegsted, D. M. (1957), J. Biol. Chem. 228, 573-576. - 32. Giorgio, J. D., Vitale, J. J. \& Helierstein, E. E. (1962), Biochem. J. 82, 184-187. - 33. SALO, M. (1970), Jap. circulation J. 34, 877, zit. nach Biochem. Abstracts. - 34. UMEZAKI, Y. (1965), Fukuoka med. J. 56, 989-1001, zit. nach MagnesiumMangel in der menschlichen Pathologie, Durlach, J. (ed) Vittel (1971). - 35. Himms-Hagen, J. (1970), Fed. Proc. Fed. Amcr. Soc. Exp. Biol. 29, 1388-1401.
Prof. Dr. Th. Günther 1 Bcrlin 33 Arnimallee 22 